\title{
Analysis of scientific papers in the field of radiology and medical imaging included in Science Citation Index Expanded and published by Turkish authors
}

\author{
Erhan Akpınar, Muşturay Karçaaltıncaba
}

\begin{abstract}
PURPOSE
We aimed to analyze scientific papers published by Turkish authors in "radiology, nuclear medicine and medical imaging" journals included in the Science Citation Index Expanded and compared the number of published scientific papers from Turkey and other countries.

MATERIALS AND METHODS

We retrospectively searched all papers published by Turkish authors between 1945 and 2008 by using Web of Science ${ }^{\circledR}$ software. We performed the analysis by typing "Turkey" in the address section and all radiology and medical imaging journals in the source title section using the general search function of the software. We further analyzed these results by using "analyze" function of the software according to the number of publications per year, journals, institution and type of papers. We also calculated total number of citations to published scientific papers using citation report function. We analyzed the rank of Turkey among other countries in terms of the number of published papers.

RESULTS

Overall, 4,532 papers were published between 1945 and 2008. The first paper was published in 1976. Number of publications increased dramatically from $1976(n=1)$ to 2008 $(n=383)$. The top 5 journals publishing papers from Turkish authors were European Journal of Nuclear Medicine and Molecular Imaging $(n=328)$, Clinical Nuclear Medicine ( = 296), European Journal of Radiology $(n=289)$, European Radiology $(n=207)$ and Journal of Clinical Ultrasound $(n=$ 186). All published papers received 18,419 citations and citation to paper ratio was 4.06 . The rank of Turkey among other countries in terms of published papers improved during the last 25 years.

CONCLUSION

Number of papers from Turkey published in radiology and medical imaging journals has increased at the start of the new millennium. Currently, Turkey is among the top 12 countries when the number of scientific papers published in radiology journals is taken into consideration.

Key words: • radiology $\bullet$ publications $\bullet$ Turkey
\end{abstract}

From the Department of Radiology (E.A. $₫$ erhan.akpinar@gmail. com), Hacettepe University School of Medicine, Ankara, Turkey.

Received 2 December 2007; revision requested 27 January 2008; revision received 24 May 2009; accepted 1 September 2009.

Published online 2 November 2009 DOI 10.4261/1305-3825.DIR.1549-07.1
$\mathbf{N}$ umber of scientific publications is an important reflection of scientific activity in a country. In recent years there has been a significant increase in the number of publications from Turkey in radiology journals (1). Science Citation Index ${ }^{\mathrm{TM}}$ (SCI) was originally introduced in 1961 as a tool for bibliographical retrieval and provides a comprehensive database for analysis of journals and publications (2). Web of Science ${ }^{\circledR}$ is a software that can be used for analysis of scientific papers indexed in the Science Citation Index Expanded ${ }^{\mathrm{TM}}$ according to various parameters. In this study, we aimed to analyze the scientific papers published by Turkish authors in radiology journals that were indexed in the Science Citation Index Expanded and compared the number of published scientific papers from Turkey and other countries.

\section{Materials and methods}

ISI Web of Knowledge ${ }^{\circledR}$-Web of Science ${ }^{\circledR}$ was used for analysis. We retrospectively searched all papers by Turkish authors between 1945 and 2008 by using Web of Science software. One hundred and seven journals were found in the radiology and imaging journal list by selecting "radiology, nuclear medicine and medical imaging" subject category in the Science Citation Index Expanded: the complete list of covered journals is reported at http://scientific.thomsonreuters.com/cgi-bin/jrnlst/jlresults. $c g i ? P C=D \& S C=V Y$, which is updated regularly. We performed the analysis by typing "Turkey" in the address section and "radiology and imaging journals" in the source title section using the general search function of the software. We further analyzed these results by using the "analyze" function of the software according to the number of publications per year, journals, hospitals and types of papers. We also calculated the total number of citations to published scientific papers. In software search, it is possible to scan maximum 50 journals at a time, therefore the analysis was completed separately as three groups and the results were assembled together as a final list. The rank of Turkey among other countries in terms of number of published papers was analyzed.

\section{Results}

Overall, 4,532 papers were published between 1945 and 2008. The first paper was published in 1976. Number of publications increased dramatically from $1976(\mathrm{n}=1)$ to $2008(\mathrm{n}=383)$ and most of the publications were articles (Table 1, Fig. 1). The top 5 journals publishing papers from Turkish authors were European Journal of Nuclear Medicine and Molecular Imaging $(\mathrm{n}=328)$, Clinical Nuclear Medicine $(\mathrm{n}=296)$, European Journal of Radiology ( $\mathrm{n}=289)$, European Radiology $(\mathrm{n}=207)$ and Journal of Clinical Ultrasound $(\mathrm{n}=186)$ (Table 2). Institutions from the three largest Turkish cities (Ankara, İzmir, and İstanbul, not in the order of their rank of population) make up the highest percentages of all publications from Turkey 


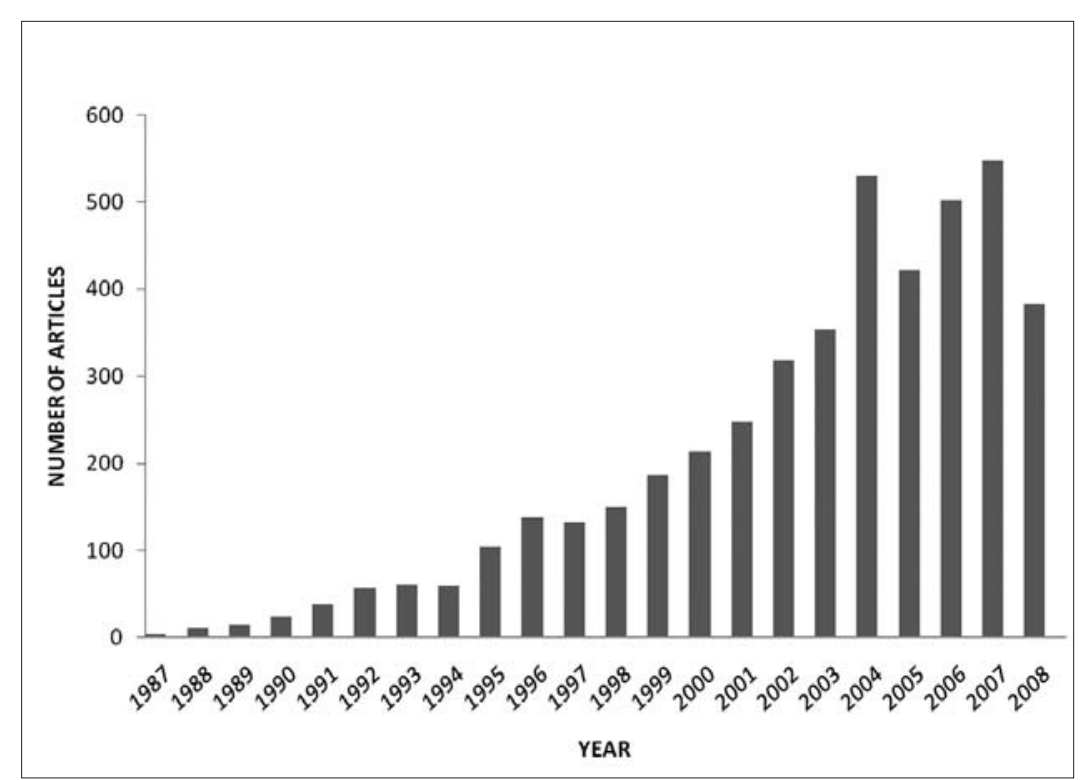

Figure 1. Publications originating from Turkey and published in journals listed by SClExpanded under the heading "radiology, nuclear medicine and medical imaging" between 1987 and 2008.

Table 1. Distribution of types of articles originating from Turkey and published in journals listed by SCl-Expanded under the heading "radiology, nuclear medicine and medical imaging" between 1976 and 2008

\begin{tabular}{lcc}
\hline Document type $^{\text {a }}$ & Number & Percentage (\%) \\
\hline Article & 3,338 & 74 \\
Meeting abstract & 473 & 10 \\
Letter & 269 & 6 \\
Editorial material & 141 & 3 \\
Proceedings paper & 140 & 3 \\
Note & 86 & 1.9 \\
Review & 69 & 1.5 \\
\hline
\end{tabular}

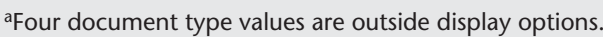

Table 2. Distribution of journals ranked by the number of publications originating from Turkey between 1976 and 2008

\begin{tabular}{lc}
\hline Journal & $\begin{array}{c}\text { Number of publications } \\
\text { from Turkey }\end{array}$ \\
\hline European Journal of Nuclear Medicine and Molecular Imaging & 328 \\
Clinical Nuclear Medicine & 296 \\
European Journal of Radiology & 289 \\
European Radiology & 207 \\
Journal of Clinical Ultrasound & 186 \\
Surgical and Radiologic Anatomy & 185 \\
American Journal of Roentgenology & 179 \\
Pediatric Radiology & 174 \\
Acta Radiologica & 171 \\
Neuroradiology & 144
\end{tabular}

(Table 3). All published papers received 18,419 citations and citation to paper ratio was 4.06 (Fig. 2). The rank of Turkey among other countries in terms of published papers has been improving during the last 25 years; between 2003 and 2007, the rank of Turkey was 11 . When the period between 1983 and 2007 was taken into consideration, the publication percentage of Turkey was 1.19 and Turkey was the fourteenth country in terms of originating country (Table 4, Fig. 3).

\section{Discussion}

Number of publications from Turkey in radiology and medical imaging journals has increased significantly in recent years and the driving force leading to increased publications in the field of radiology from Turkey appears to be the rapid adaptation to imaging technology and improved education. It is interesting to note that Turkey was listed among the top 5 countries which submitted scientific papers to American Journal of Roentgenology (3). Analysis of articles published by American Journal of Roentgenology between 1980 and 2002 showed a continually increasing number of international articles during the past decades. The same analysis also disclosed an increasing number of publications by Turkish authors in the same period (4). With the share of $3.3 \%$ of published articles, Turkey has been a major contributor to American Journal of Neuroradiology, ranking sixth among countries outside the Unites States (5). During 1991-2000, the share of articles in clinical radiology from Turkey has increased and the share of articles from Israel has decreased. South Korea and People's Republic of China are the two other countries with a trend similar to that of Turkey (6). In our opinion, the main factor for increased publications from Turkey is the extensive investment in human resources and technology in university, government and private hospitals and clinics. Today, there are 61 university hospitals in Turkey, which constitute the core of increased academic productivity. Also, private centers and government teaching hospitals play a great role in the increased number of publications in the field of radiology. Moreover, radiologists who did fellowship (mostly in United States) and learned scientific writing abroad returned to Turkey 
Table 3. Distribution by institutions of articles originating from Turkey and published in journals listed by SCl-Expanded under the heading "radiology, nuclear medicine and medical imaging" between 1976 and 2008

\begin{tabular}{lc}
\hline Institutions & $\begin{array}{c}\text { Number of } \\
\text { publications }\end{array}$ \\
\hline Hacettepe University & 690 \\
Istanbul University & 473 \\
Ege University & 460 \\
Ankara University & 279 \\
Gülhane Military Medical Academy & 222 \\
Başkent University & 221 \\
Gazi University & 213 \\
Dokuz Eylül University & 189 \\
Akdeniz University & 126 \\
Trakya University & 124
\end{tabular}

Table 4. Distribution by countries of items published in journals listed by $\mathrm{SCl}$-Expanded under the heading "radiology, nuclear medicine and medical imaging" between 1983 and 2007

\begin{tabular}{lc}
\hline Country & Percentage \\
\hline USA & 41.58 \\
Germany (Federal Republic of Germany) & 8.65 \\
England & 7.42 \\
Japan & 6.43 \\
Canada & 4.49 \\
France & 4.07 \\
Netherlands & 2.86 \\
Italy & 2.77 \\
Belgium & 1.59 \\
South Korea & 1.56 \\
Sweden & 1.51 \\
Switzerland & 1.50 \\
Austria & 1.21 \\
Turkey & 1.19 \\
Spain & 1.17 \\
Australia & 1.13 \\
\hline
\end{tabular}

and contributed substantially to the increased productivity in the field of radiology (1).

Turkish Society of Radiology and other national subspecialty societies organize meetings every year to train radiology residents and specialists

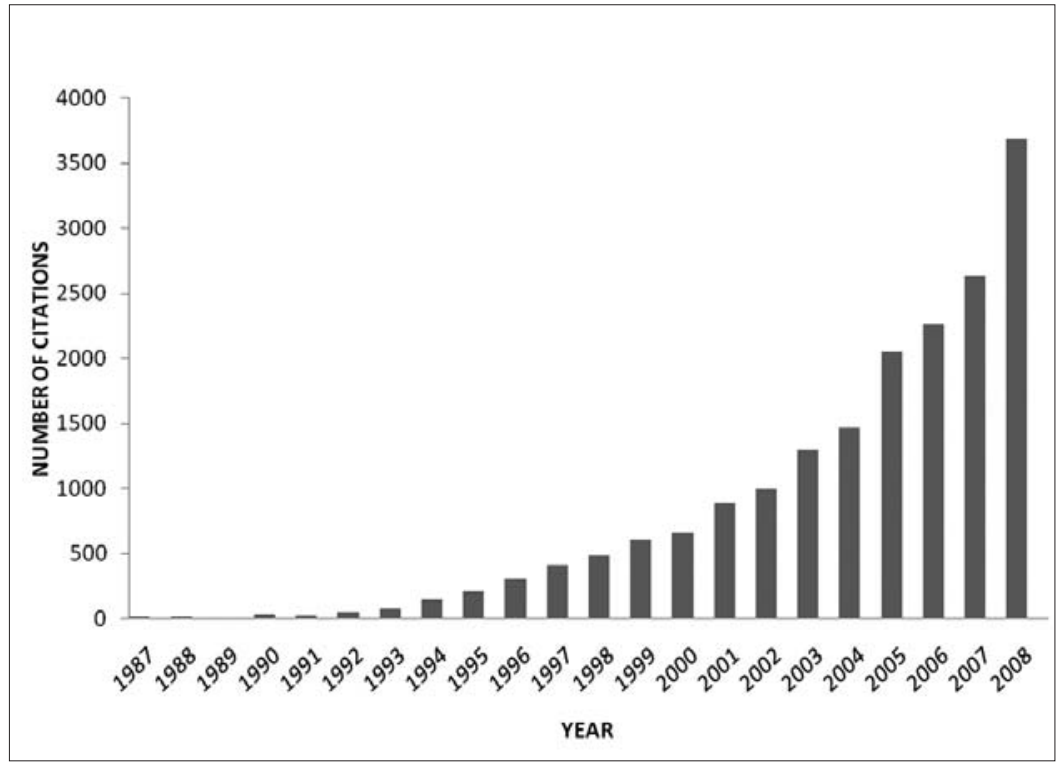

Figure 2. Citations in journals to articles originating from Turkey and listed by SClExpanded under the heading "radiology, nuclear medicine and medical imaging" between 1987 and 2008 .
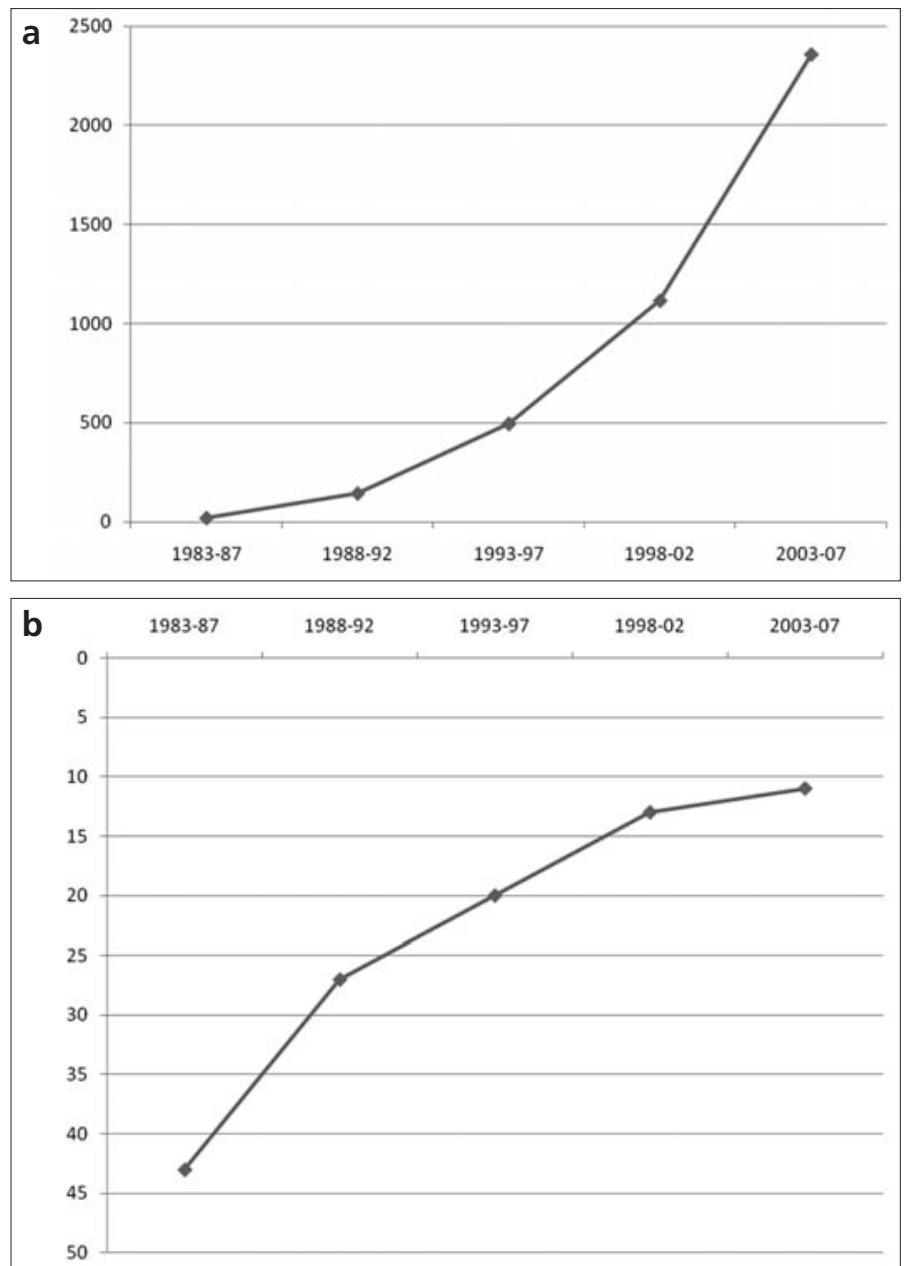

Figure 3. a, b. Charts showing changes between 1983 and 2007 in the number of radiology and medical imaging publications originating from Turkey (a) and the rank of Turkey among other countries (b). The rank of Turkey among other countries improved in accordance with the increased number of publications. 
with international faculty attendance. In such scientific meetings, practitioners have the chance to present and exchange their ideas about their branches. At the 28th Turkish Congress of Radiology, 166 scientific papers and 779 e-posters were presented. High publication rates of valuable information presented in these scientific meetings can be considered as a parameter of the quality of the meetings. During the publication period abstracts are expanded into full-text manuscripts and a more rigorous review process of study design, methods and conclusions happens $(7,8)$. Eventual publication rate of the European Congress of Radiology (ECR) submissions was 39\%, and the country of origin of an abstract was useful in predicting the chances of eventual publication of an abstracted study/report, with the United States having the highest publication rate (8). Only $21 \%$ of orally presented abstracts at the ECR 2001 originating from Turkey were eventually published (9). The publication rates of abstracts presented at the Turkish national radiology congress between 1995 and 2002 are lower than the previously reported publication rates in radiology and other specialties (10). The relatively low publication rate can be due to lack of motivation to publish the manuscripts and high manuscript rejection rates. Reasons for rejection of manuscripts include, lack of new or useful knowledge, logical or methodologic errors, errors in data analysis, and inadequate language quality (3). Encouragement, promotions and scientific writing education will be helpful for increasing the publication rate. Improvement can also be ensured by frequent communication between departments and universities and by using well-developed working models (11).

The fact that our study analyzed only radiology and medical imaging journals is a limitation. This can cause overestimation or underestimation of radiological scientific production. Another handicap that we encountered during the study was the uncertainty of addresses of some researchers. Addresses from the same university, even from the same department, could be different. The standardization of the addresses carries importance. It may be hard to obtain articles published before 1980 as addresses are not always registered on online archives. As the journal list is updated regularly, the numerical changes in the results should also be taken into consideration.

In conclusion, number of papers from Turkey published in radiology and medical imaging journals has recently increased and Turkey can be a model for other countries starting to thrive in the field of radiology and medical imaging.

\section{References}

1. Karcaaltincaba M. Radiology in Turkey: what is happening? AJR Am J Roentgenol 2007; 189:1283-1284.

2. Andersen J, Belmont J, Cho CT. Journal impact factor in the era of expanding literature. J Microbiol Immunol Infect 2006; 39:436-443.

3. Ehara S, Takahashi K. Reasons for rejection of manuscripts submitted to AJR by international authors. AJR Am J Roentgenol 2007; 188:W113-116.

4. Chen MY, Jenkins CB, Elster AD. Internationalization of the American Journal of Roentgenology: 1980-2002. AJR Am J Roentgenol 2003; 181:907-912.

5. Cloft HJ, Cloft KJ. How American is the American Journal of Neuroradiology? AJNR Am J Neuroradiol 2007; 28:601.

6. Rahman M, Haque TL, Fukui T. Research articles published in clinical radiology journals: trend of contribution from different countries. Acad Radiol 2005; 12:825-829.

7. Ng L, Hersey K, Fleshner N. Publication rate of abstracts presented at the annual meeting of the American Urological Association. BJU Int 2004; 94:79-81.

8. Miguel-Dasit A, Martí-Bonmatí L, Aleixandre R, Sanfeliu P, Bautista D. Publication of material presented at radiologic meetings: authors' country and international collaboration. Radiology 2006; 239:521-528.

9. Miguel-Dasit A, Martí-Bonmatí L, SanfeliuMontoro A, Aleixandre R, Valderrama JC. Scientific papers presented at the European Congress of Radiology: a two-year comparison. Eur Radiol 2007; 17:1372-1376.

10. Seçil M, Uçar G, Sentürk C, Karasu S, Dicle O. Publication rates of scientific presentations in Turkish national radiology congresses. Diagn Interv Radiol 2005; 11:69-73.

11. Küpeli S, Akpınar E. Turkish authors in international medical journals. Yeni Tip Dergisi 1996; 13 Supp:22-23. 